\title{
COMUNICAÇÃO OMNICHANNEL: CONVERGINDO RELACIONAMENTOS E EXPERIÊNCIAS OFF-LINE E ON-LINE
}

\author{
Omnichannel communication: converging off-line and on-line \\ relationships and experiences
}

\author{
Comunicación omnichannel: convergencia de relaciones \\ y experiencias off-line e on-line
}

\author{
Fabio Frá Fernandes \\ Doutorando no Programa de Pós-Graduação em Comunicação \\ da Universidade Federal de Santa Maria \\ fabio.fra.fernandes@outlook.com \\ Marcela Guimarães e Silva \\ Professora do Programa de Pós-Graduação em \\ Comunicação e Indústria Criativa \\ da Universidade Federal do Pampa \\ marcelaunipampa@gmail.com
}

\section{Resumo}

Este artigo busca refletir sobre a perspectiva omnichannel, aqui apropriada para pensar a comunicação como forma de garantir relacionamentos e experiências similares em todos os canais que uma organização dispõe. Metodologicamente, este texto parte de um breve estado da arte sobre a sociedade em rede e a ressignificação dos territórios mediados pelo digital; sobre as redes sociais digitais como propulsores da comunicação ubíqua e, ainda, como esses conceitos ajudam a compreender e exercitar a ideia de comunicação omnichannel. Desses conceitos, é apresentado um breve relato sobre as estratégias de comunicação omnichannel do Grupo Boticário, a partir da leitura de uma palestra realizada pelo seu diretor de e-commerce Guilherme Farinelli. Com essa articulação, é possível perceber como pode ser colocada em prática a comunicação omnichannel, e como ela se reflete nas relações entre marca e públicos.

Palavras-chave: Omnichannel. Comunicação. Grupo Boticário.

\begin{abstract}
This article seeks to reflect on the omnichannel perspective, here appropriate to think of communication as a way to guarantee similar relationships and experiences in all the channels that an organization has. Methodologically, this text starts from a brief state of the art about the networked society and the re-signification of territories mediated by digital; on digital social networks as drivers of ubiquitous communication, and how these concepts help to
\end{abstract}


understand and exercise the idea of omnichannel communication. From these concepts, a brief report on the omnichannel communication strategies of the Grupo Boticário is presented, based on a lecture given by its e-commerce director, Guilherme Farinelli. With this articulation, it is possible to understand how omnichannel communication can be put into practice, and how it reflects in the relations between brand and public.

Keywords: Omnichannel. Communication. Grupo Boticário.

\section{Resumen}

Este artículo busca reflexionar sobre la perspectiva omnichannel, aquí apropiado para pensar en la comunicación como una forma de garantizar relaciones y experiencias similares en todos los canales que tiene una organización. Metodológicamente, este texto parte de un breve estado del arte sobre la sociedad de redes y la redefinición de territorios mediados por medios digitales; sobre las redes sociales digitales como impulsores de la comunicación ubicua, y también cómo estos conceptos ayudan a comprender y ejercitar la idea de la comunicación omnichannel. De estos conceptos, se presenta una breve reseña de las estrategias de comunicación omnichannel del Grupo Boticário, basada en la lectura de una conferencia dada por su director de comercio electrónico Guilherme Farinelli. Con esta articulación, es posible ver cómo se puede poner en práctica la comunicación omnichannel y cómo se refleja en la relación entre la marca y el público.

Palabras llave: Omnichannel. Comunicación. Grupo Boticário.

\section{INTRODUÇÃO}

No contemporâneo, um incomensurável número de dispositivos e aplicativos tecnológicos com as mais variadas funções, estão à disposição de qualquer pessoa. Tendo em mão um único dispositivo, como um smartphone, é possível se comunicar por voz, por vídeo, por mensagens, mas também acessar portais de notícias, portais institucionais, plataformas de compra, estar presente nas mais variadas redes de relacionamento digital, consumir música, filmes, arte e, ainda, por meio de outras aplicações instaladas, controlar desde o aparelho de televisão até acionar outros dispositivos elétricos e eletrônicos.

A integração de múltiplas plataformas, sistemas e aplicações dificultam hoje a separação entre os ambientes off-line e on-line. Pessoas e organizações ao redor do mundo vivem simultaneamente em territórios físicos e digitais e, suas relações, sejam pessoais, negociais ou de consumo estão, de uma forma ou outra, coexistindo entre esses ambientes.

Se o desenvolvimento de tecnologias, em especial as da comunicação e informação, bem como a multiplicação de seus meios, se integraram de forma exponencial na vida das pessoas, nas organizações esse processo não é diferente. Se antes as estratégias de comunicação se limitavam ao uso de alguns canais para estabelecerem relacionamentos 
estratégicos, hoje as opções de canais são bem mais significativas e complexas. E-mails, redes sociais, blogs, portais digitais, aplicativos de mensagem instantânea, aplicativos institucionais, plataformas de compra e chatbots são alguns dos exemplos de canais disponíveis, não apenas às organizações sociais, mas ao público em geral, que demanda sua utilização e exige processos comunicacionais coerentes e alinhados em cada um deles. A integração dos processos comunicacionais e relacionais nos ambientes off-line e on-line pode ser denominada como comunicação omnichannel.

Oriunda de estratégias da administração, com foco no consumo de varejo, o termo omnichannel busca caracterizar a integração dos canais de comunicação e relacionamento durante a experiência de consumo dos públicos de uma organização, sejam eles no off-line ou no on-line. Sob a ambiência omnichannel, o público pode conhecer, experienciar e consumir um produto ou serviço nos ambientes digitais de uma marca e conseguir efetuar a compra ou experimentar o serviço ou produto em algum dos seus ambientes físicos. O caminho inverso também deve ser possível na ambiência omnichannel, experienciando e consumindo em espaços físicos, mas finalizando o ato de compra, por exemplo, em ambientes digitais.

Os públicos de uma organização, em especial aqueles multiconectados, exploram as possibilidades de interação consumindo e produzindo conteúdo. Se aproximam das marcas (organizações) exigindo transparência, atendimento em tempo real, soluções para suas necessidades. Desejam que suas experiências sejam simétricas, tanto nos ambientes off-line quanto nos ambientes on-line. Ou seja, as formas de comunicação e relacionamento entre o público e uma organização não deve ser diferente conforme o ambiente. Se uma marca afirma em seus canais digitais processos de qualidade, bom atendimento, preço, agilidade na entrega, formas de pagamento e curadoria na produção de conteúdo, quando transmutada para canais de comunicação e relacionamento off-line, esses mesmos processos precisam acontecer igualmente.

Essa é a configuração da ambiência omnichannel, onde as sociabilidades não são separadas entre físico e digital, mas unificado na vida das pessoas e de suas organizações. $\mathrm{O}$ omnichannel determina a unificação dos canais, ou seja, os públicos ao circularem entre os múltiplos canais de comunicação e relacionamento disponíveis, sob esta perspectiva, não devem perceber diferenças na experiência com a marca/organização. Eles precisam encontrar o mesmo processo relacional, permitindo a multiconectividade, livre circulação e todas as informações necessárias, igualmente, no on-line ou no off-line. Igualmente não no sentido de 
reprodução de conteúdo, mas de informações disponíveis e adaptadas para cada plataforma. Mas seguindo a perspectiva da experiência unificada.

O termo omnichannel surge de indagações do mercado, de profissionais que não acreditam mais na separação entre os ambientes off-line e on-line para a execução de suas estratégias, sejam de comunicação, administração ou marketing. De modo muito instantâneo o termo gera modelos de aplicações, é apropriado por organizações de vários segmentos e, por seus resultados nos processos de gestão, se apresenta como um diferencial de mercado. A perspectiva omnichannel é o reflexo das transformações culturais e sociais que as tecnologias ocasionam sobre as pessoas e, consequentemente, sobre as organizações sociais. É um modelo de comportamento que, para ser atendido comercialmente, demanda estratégias específicas. Mas, indo além, a ideia de uma ambiência omnichannel para as organizações, exige delas mais que estratégias, e sim mudanças em sua cultura organizacional, em seus processos de gestão e de comunicação.

Do contexto apresentado, este artigo se propõe a refletir sobre a perspectiva omnichannel, no âmbito da comunicação, como um vetor para aperfeiçoar e potencializar estratégias organizacionais para relacionamento e engajamento público. Para construir o pensamento-reflexivo, parte-se de um breve estado da arte sobre a configuração da sociedade em rede e dos diferentes entendimentos sobre territorialidades, sendo esse um primeiro caminho para se pensar a comunicação em perspectiva e ambiência omnichannel. É articulado também, a emergência das redes sociais digitais como um processo latente na atualização das normas e formas de interação social e negocial na contemporaneidade, para então, constituir um entendimento sobre a comunicação omnichannel e suas características.

Para complementar as abordagens teóricas, o texto ainda relata, de modo objetivo, a experiência de transição comunicacional do Grupo Boticário. A partir da leitura de uma palestra realizada pelo diretor de e-commerce do Grupo, Guilherme Farinelli ${ }^{1}$, durante o VTEX DAY, é exemplificado as estratégias adotadas para a construção de sua ambiência omnichannel sobre vendas, relacionamentos e manutenção de marca.

A experiência do Grupo Boticário sobre a ambiência omnichannel não se apresenta como objeto principal de estudo neste artigo, mas sim como subsídio para qualificar as abordagens teóricas articuladas, ao passo de também promover melhor visualização empírica

\footnotetext{
${ }^{1}$ Guilherme Farinelli esteve à frente do departamento de e-commerce do Grupo Boticário de 2015 a 2018 , período em que este artigo foi produzido. Atualmente, Guilherme atua como Diretor de Transformação Digital da Cia Hering.
} 
sobre a efetivação de estratégias comunicacionais e relacionais em perspectiva omnichannel para diferentes organizações. Discutir a veracidade ou eficácia do que é informado pelo Grupo, não é interesse deste trabalho.

\section{APONTAMENTOS SOBRE A SOCIEDADE EM REDE E SUAS TERRITORIALIDADES}

A conjugação da internet com os fenômenos comunicacionais e relacionais favoreceram certa (re)configuração da sociedade, onde formas contemporâneas de interação e pertencimento social são estabelecidos (CARDOSO, 2005). A chegada do novo século (XXI) impulsionou esse cenário, onde as pessoas e organizações passam a viver, como afirma Manuel Castells, na sociedade em rede. Ou seja, uma sociedade hipersocial, sem isolamento, onde as pessoas têm as tecnologias integradas às suas vidas, ligando a realidade virtual com a virtualidade real e vivendo as várias formas tecnológicas da comunicação, em articulação com suas necessidades (CASTELLS, 2016)

O fim da segunda década do século XXI, tem a internet integrada à todos os processos sociais e organizacionais. Cotidianamente, novas ferramentas, aparelhos, aplicativos, canais, páginas on-line e sistemas são produzidos e disseminados mundo afora. O que era possível ser feito em frente a um computador em 2010, hoje é feito de forma mais ampla, e em aparelhos de telefonia móvel, wearables e tablets. A internet na atualidade é móvel, integradora e sem limites territoriais.

Com a comunicação mediada por múltiplas plataformas de relacionamento digital, temos a flexibilização dos territórios e das formas de ser, estar, pertencer e relacionar-se (BARICHELLO, 2012). A sociedade em rede libera barreiras territoriais. Hoje os indivíduos coexistem igualmente nos ambientes físicos e digitais, exigindo das organizações o mesmo comportamento: múltiplos ambientes, múltiplas plataformas de conexão.

O processo de territorialização digital acontece quando os indivíduos desenvolvem novas formas de pertencer e relacionar-se socialmente em outro espaço, não físico, mas munido de simbologias e mediado pela comunicação que estrutura um novo território, com cultura diferente (formada através da aglutinação da cultura individual dos seus membros) e em constante desenvolvimento. Esse novo pertencimento seria a reterritorialização do indivíduo (BARICHELLO, 2012). 
Para Pierre Lévy (2011) o processo de desterritorialização vivenciado pelo indivíduo no campo digital, seria o momento em que ele se virtualiza, pois é desprendido de seu contexto, e automaticamente atualizado (reterritorializado) nesse novo contexto. O território virtual não é representado por um novo espaço, mas sim por um conjunto de conexões possíveis e estabelecidas pelos usuários, sempre vinculado ao seu espaço físico. Esse espaço será atualizado em termos de eficácia produtiva e cultural pelo uso que, os indivíduos e suas organizações, dele o fazem (BARICHELLO, 2012).

$\mathrm{Na}$ comunicação reterritorializada no ciberespaço tem-se como entendimento que o usuário pode viver ubiquamente, ou seja, estar em dois lugares ao mesmo tempo. Cenário possível, conforme Santaella (2013), pela conectividade digital quase que existente em todos os lugares, que permite às pessoas e organizações estarem reunidas, trabalhando e vivendo em seus territórios físicos e, em tempo real, vivendo e trabalhando nos territórios digitais que participam.

A dimensão do local não pode e não deve ser esquecida quando se fala ou se estuda a territorialidade da comunicação e dos relacionamentos no mundo digital. A existência de territórios virtuais somente é possível pela coexistência com os territórios físicos e das possibilidades de interação e comunicação entre eles (BARRICHELLO, 2012). No contexto atual, os conteúdos locais (do pertencimento físico), estão muito ligados com a produção de conteúdo na internet (do pertencimento virtual), de modo a ressaltar a sobrevivência das redes sociais na internet a partir da significação que a mesma representa para seus entes que mesmo virtuais, são também reais, e agem também nas comunidades não virtuais. Ocorre aqui a confluência de interesses e objetivos. O real e o virtual interligado, interdependente e ubíquo (SANTAELLA, 2013).

Organizações, quando reterritorializadas nas comunidades virtuais, também carecem de entendimento e compreensão sobre os fatores mecânicos e administrativos, bem como dos processos simbólicos de comunicação e relacionamento, pois estará pertencendo a um novo espaço cultural, e nele, com objetivos diferentes ou adaptados. Transformações tecnológicas e sociais que afetam e alteram essas estruturas organizacionais (BARICHELLO, 2006). Dessa intensa mudança, as relações sociais e culturais tornam-se ainda mais latentes no corpus das organizações. A final, a vivência na sociedade em rede é pautada pelas relações públicas de seus indivíduos, e esses, dotados culturalmente de símbolos e significações distintas, que se fundem e estruturam a cultura das redes (CASTELLS, 2016). Perspectiva que faz a 
confluência entre a cultura vivida nas redes virtuais com a cultura da organização, bem como com à ávida midiatização social e organizacional

Aqui, as possibilidades de interação aumentam, e os indivíduos produzem conteúdo tanto quanto as organizações e a própria mídia tradicional. A sociedade em rede possibilita o aumento da participação e engajamento público. Os atores sociais não aceitam mais receber a informação, a cultura de massas, e passam a produzir seu próprio conteúdo, seus espaços de participação (BARICHELLO, 2012), exigindo da comunidade e de suas organizações maior retorno, transparência e participação.

\section{REDES SOCIAIS DIGITAIS: COMUNICAÇÃO NA SOCIEDADE EM REDE}

No cenário exposto anteriormente, as redes sociais digitais ganham influência, e se tornam grandes aliadas para as organizações em suas relações públicas, permitindo a interação em tempo real, desenvolvendo engajamento organizacional com usuários destas redes, e ainda favorecendo a circulação do saber e a formação de inteligência coletiva (LÉVY, 2011). São elas, redes sociais digitais, potencializadoras da ubiquidade da comunicação (SANTAELLA, 2013).

Recuero afirma que as redes sociais digitais constituem-se como um espaço para a exposição e publicização das comunidades digitais e dos atores com elas envolvidos. São formadas por um conjunto de dois elementos: atores sociais (pessoas, instituições ou grupos, nós da rede) e conexões (interações e laços sociais). Uma rede é, assim, uma metáfora utilizada para se observar padrões de conexões de um grupo a partir das conexões que eles estabelecem com outros grupos e indivíduos (RECUERO, 2014).

É possível observar que a maior mudança proporcionada pelas redes sociais digitais, é a permissão para qualquer indivíduo ser consumidor, produtor e transmissor de informação (MAINIERI, 2011). Essas características de atuação dos atores sociais nas redes de relacionamento na internet favorecem o desenvolvimento de uma comunicação organizacional onipresente, ou seja, simultânea em todos os canais possíveis e utilizados para que a comunicação e os relacionamentos se efetivem.

Compreender o fazer da comunicação no cenário tecnológico e digital, com a amplitude da sociedade em rede, é uma constante na vida das organizações que vislumbram novas estratégias de comunicação e relacionamento mediadas por redes sociais na internet. 
Hoje as organizações precisam sincronizar e tornar indissociáveis suas estratégias de comunicação tradicional com as estratégias de comunicação digital. É preciso o alinhamento e adequação das mensagens, da linguagem e da tipologia visual e gráfica para que a convergência midiática ocorra de forma eficaz, alcançando seus variados públicos.

A sociedade em rede exige das organizações perspectivas comunicacionais mais instantâneas e ubíquas. As pessoas desejam que as experiências nos ambientes off-line sejam iguais nos ambientes on-line, e em tempo real. Reside aqui, a ideia de organizações e indivíduos em experiências de ubiquidade e conectados ao conceito de omnichannel. $\mathrm{Na}$ atualidade, as organizações que apenas figuram nas mídias sociais mais populares, sem objetivo e planejamento estratégico, perdem espaço no mercado e seus públicos de interesse migram para outras organizações que possuam maior aderência e eficácia nas práticas comunicacionais e relacionais.

\section{COMUNICAÇÃO OMNICHANNEL: CONVERGÊNCIA ENTRE OFF-LINE E ON-}

\section{LINE}

Com base no entendimento da sociedade em rede, do processo de reterritorialização, da possibilidade de viver de modo ubíquo on-line e off-line, algo que é potencializado pela internalização das mídias e redes sociais digitais na vida da sociedade, é possível perceber a ampliação nas formas e modos de relacionamento, comunicação e consumo de pessoas e organizações. Existe a ressignificação dos limites territoriais e a oferta, quase que incomensurável, de plataformas físicas e digitais para comunicação e relacionamento. Hoje, um indivíduo não quer apenas se conectar com um único canal, mas sim com todos os canais possíveis. Cenário que modela a ideia de uma ambiência omnichannel para comunicação e relacionamentos organizacionais.

Omni, do latim, significa "tudo" e channel, traduzido do inglês, significa "canal". Assim, dessa significação etimológica percebe-se que, comunicação apropriada do significado de omnichannel, consiste no conteúdo comunicativo (relacionamento) disponível em todos os canais conforme a especificidade de cada meio e dos públicos-usuários.

A perspectiva estratégica da comunicação omnichannel de uma organização, a partir do conceito apresentado, busca comunicar uma imagem integrada em todos os canais utilizados, ou seja: on-line (sites institucionais e de $e$-commerce, aplicativos, redes sociais, $e$ mail, chatbots, assistentes virtuais); off-line (impressos, rádio e televisão, revistas, catálogos); 
in-store (merchandising, layout de loja); endomarketing; ou em qualquer outro ponto de contato possível e utilizado.

Para entender a comunicação omnichannel, é necessário compreender a cronologia de transição comunicacional das organizações. Sendo: (1) primeiro canal - pessoas apenas se relacionam com a marca (organizações) em ambientes físicos; (2) segundo canal - as pessoas passam a estabelecer relações organizacionais em ambiência digital (websites); (3) multicanal - os relacionamentos permeiam linearmente os territórios físico e digital, mas ainda com certo isolamento; (4) omnichannel - as pessoas passam a se relacionar com a marca através de todos os canais (plataformas) disponíveis sem distinção (COELHO, 2015).

Devido a esse comportamento, em especial no âmbito do consumo no varejo, que o conceito de omnichannel ganha força. Sendo ele a compreensão de que todos os canais de uma marca são integrados para atender seu público, não importando de qual canal ele veio, mas sim sobre a experiência que ele teve. Integração total entre o on-line e o off-line (FAGUNDES, 2017). Omnichannel é a estratégia que unifica "todos os canais" [grifo nosso], onde as experiências e sensações de relacionamento (comunicação) aconteçam de modo análogo (COELHO, 2015). Não importa se a comunicação seja mercadológica ou institucional, sua essência, estética e objetivo devem ser as mesmos, tendo apenas a linguagem formatada conforme as características de cada canal e seus usuários (FAGUNDES, 2017).

No contexto omnichannel, os públicos se moldam enquanto indivíduos sempre informados, conectados, sofisticados e muito conscientes quanto as relações com marcas e organizações. A informação sobre produtos e serviços é adquirida através dos diferentes meios e mídias disponíveis, mas agora em simultâneo, ao contrário do que acontecia no modelo multicanal (COELHO, 2015). Na figura abaixo, é apresentado algumas possibilidades de públicos para organizações. 
Figura 01 - públicos de interesse de uma marca/organização

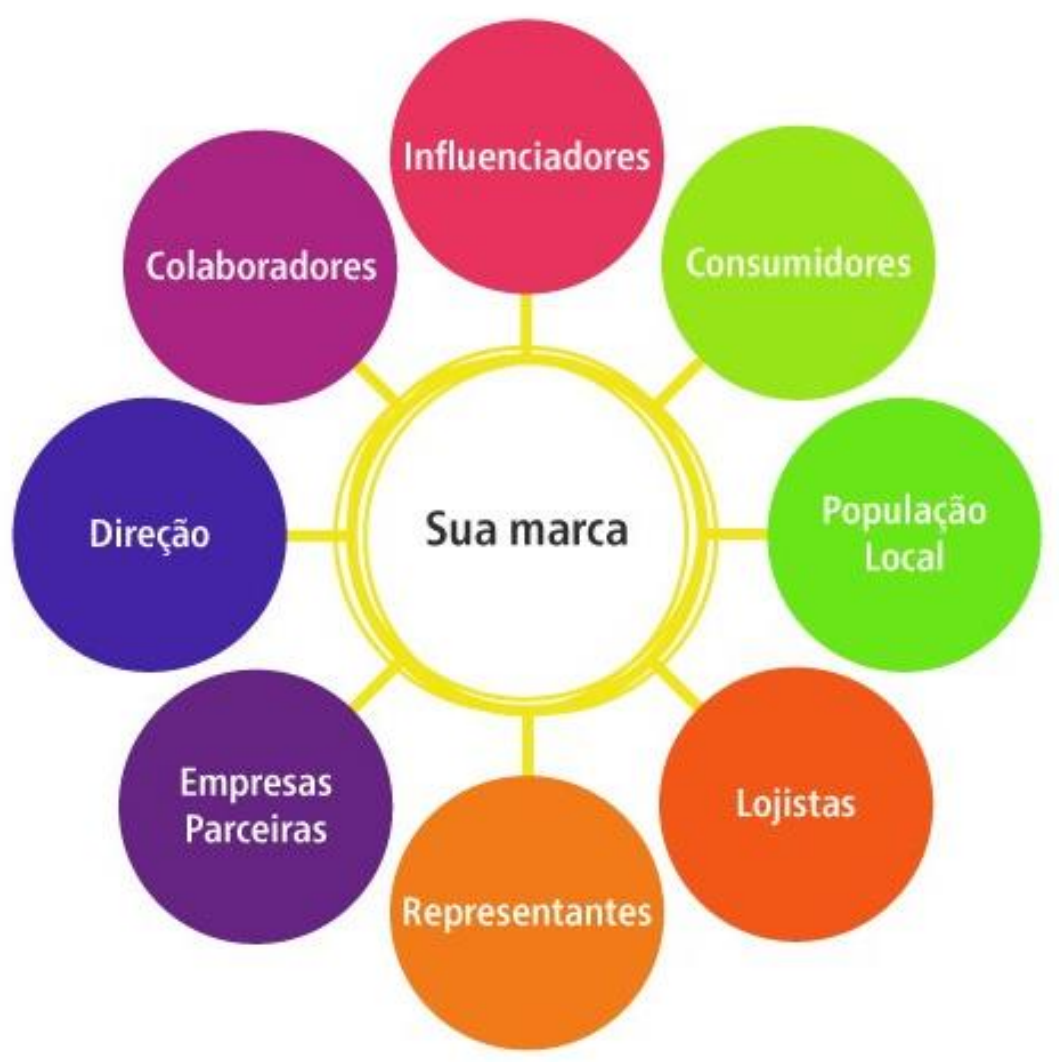

Fonte: Champs Agência

É possível perceber, na figura acima, um quantitativo de públicos significativo, com possibilidades muito caras para qualquer marca/organização no que tange seus relacionamentos estratégicos. Cada segmento de público tem certo diferencial, dependendo do objetivo da ação ou do planejamento global de comunicação empreendido para eles. Esses públicos, que podem ser omnichannel, segundo Dias (2014), querem todas as vantagens do relacionamento digital, mas também as possibilidades dos espaços físicos, do contato face a face, das experiências sociais em ambiência física e ainda transmitir essas sensações para sua rede de conexões digitais em tempo real. 
Figura 02 - canais de comunicação e relacionamento para cada público de uma marca/organização

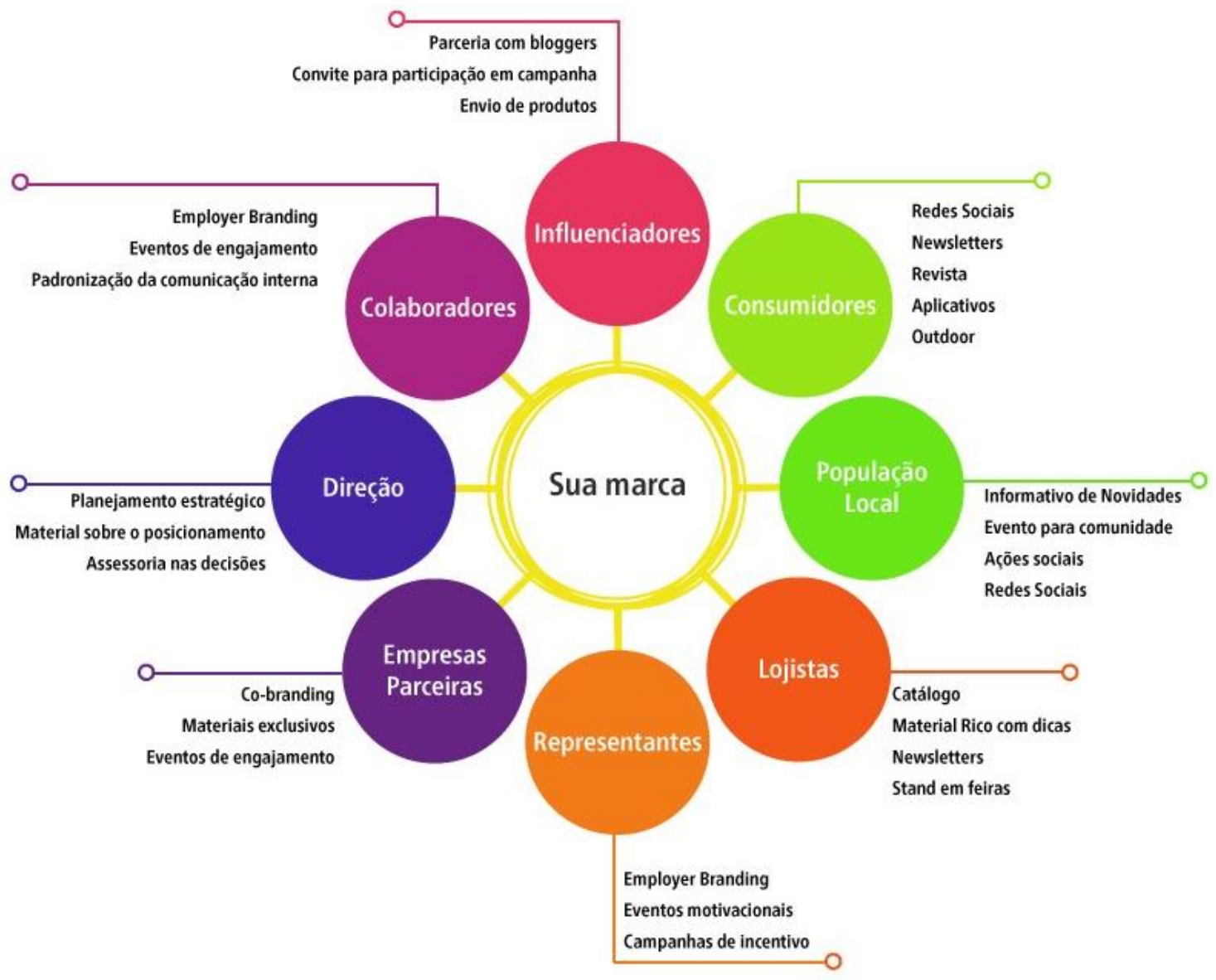

Fonte: Champs Agência

Ao olhar as possibilidades de comunicação omnichannel com esses públicos, a figura 02 ilustra a quantidade de canais que uma organização possui e, que muitas vezes nem os compreendem enquanto canais de comunicação e relacionamento. Por isso, uma organização para ser omnichannel precisa conhecer em profundidade seu público de interesse, sua cultura e seu comportamento, além da clareza sobre todos os seus canais. Ela precisa desenhar e planejar cada processo de comunicação, independente de seus objetivos serem negociais ou relacionais, de modo a oferecer as mesmas possibilidades de interação, sociabilidade e consumo ubíquo para seus públicos.

Uma organização, sob a perspectiva omnichannel, precisa estabelecer estratégias comunicacionais e relacionais uniformes em todos os seus canais, empregando a mesma linguagem e de forma homogênea para que seu público de interesse, aquele, que navega nos 
seus mais diversos canais de comunicação, relacionamento e de vendas, possa enxergá-la como uma unidade e assim facilitar sua jornada nestes espaços.

Na comunicação omnichannel, é preciso também, através da integração dos canais de relacionamento e de venda, que o público (ou cliente de forma mais específica) se perceba como único para a organização, sendo tratado da mesma forma em todos os pontos de contato. Cabe, portanto, às organizações encontrarem a sinergia correta para atender essa demanda, além de tornar efetiva e eficaz em seu modus operandi, a comunicação omnichannel.

\section{COMUNICAÇÃO OMNICHANNEL DO GRUPO BOTICÁRIO: HARMONIA ENTRE E-COMMERCE E FRANQUEADOS}

Dos conceitos articulados anteriormente é apresentado nesta seção, a apropriação do conceito e prática da perspectiva omnichannel pelo Grupo Boticário para pensar e executar suas estratégias de comunicação e relacionamento. O Grupo Boticário é uma das primeiras organizações no Brasil a utilizar a perspectiva omnichannel em suas estratégias de comunicação e relacionamento. É também uma das poucas a divulgar sua experiência de transição comunicacional em veículos ou eventos especializados no assunto. Por isso, sua experiência é abordada aqui, para promover uma melhor visualização empírica sobre a efetivação de estratégias comunicacionais e relacionais em perspectiva omnichannel.

As informações que formam esta seção são oriundas de uma palestra proferida pelo gestor de e-commerce do grupo, Guilherme Farinelli, durante a VTEX DAY 2017, um evento de negócios que reúne empresários, empreendedores e públicos afins, para discutir tendências de mercado e apresentar casos de sucesso e inovação.

O contexto organizacional do Grupo Boticário é delimitado por quatro marcas distintas: O Boticário; Eudora; Quem Disse, Berenice?; e The Beauty Box. Sua atuação abrange todo o território brasileiro e também se expande para o comércio internacional, desenvolvendo produtos do segmento de beleza. Suas vendas acontecem em lojas físicas, compreendidas por franqueados do Grupo, além de consultores de venda autorizados (esses principalmente em localidades sem a presença de lojas físicas) e pelo serviço de $e$-commerce. Os processos comunicacionais e relacionais do Grupo, portanto, são tangenciados nos ambientes on-line e off-line. 
Durante sua apresentação no VTEX DAY, Guilherme descreve o processo de transição comunicacional do grupo, ponderando as etapas que envolveram o planejamento e execução de todas as fases, ou seja, os quatro estágios para que a organização se tornasse omnichannel. Conforme afirma Coelho (2015), para uma organização transacionar seus processos de comunicação e relacionamento, ela terá de aperfeiçoar suas práticas e meios, evoluindo dos canais puramente off-line ou on-line, para canais que convergem off-line e on-line em uma só experiência.

Com o Grupo Boticário, esse processo aconteceu evolutivamente com: [1] primeiro canal: período em que a organização estava presente no mercado apenas com suas lojas físicas; [2] segundo canal: quando o Grupo passa a contar com consultores de vendas e com o site comercial como complemento das lojas físicas, mas sem integração entre estes canais; [3] multicanal: quando o Grupo passa a integrar os ambientes off-line com o on-line, mas isto de forma isolada; e a [4] consolidação da comunicação omnichannel, fase atual do Grupo onde a comunicação e os relacionamentos estão focados nas experiências de uso e de consumo de seus públicos, exigindo integração total de seus canais para que essas experiências sejam possíveis, respeitando as características do público omnichannel e, ainda, para o compartilhamento das mesmas num processo de consumo ubíquo.

Reforçar e aumentar a presença digital no contemporâneo não significa reduzir contato nos espaços físicos, mas permitir outras formas de contato, relacionamento, experiências e consumo. On-line e off-line se completam, não são concorrentes. Mas, para isso, é necessário o alinhamento entre a cultura organizacional com as estratégias e posicionamento de mercado, de modo a alinhar o consumo, por exemplo, tanto em ambiência digital, quanto física.

Guilherme explica alguns dos posicionamentos do Grupo no âmbito da comunicação omnichannel. Uma campanha de comunicação e relacionamento, ou mesmo de promoção e divulgação on-line, segundo Guilherme, é um exemplo que demanda planejamento mais instantâneo, focado no que está acontecendo naquele minuto nas redes sociais digitais, onde se elabora e publica conteúdos que atendam à demanda específicas. Situação que, em ambientes off-line, não seriam possíveis, sendo que estes espaços demandam maior planejamento, recursos físicos e materiais.

Outra questão importante da comunicação omnichannel do Grupo posto por Guilherme, é a possibilidade de trabalhar com múltiplas campanhas. Nas lojas físicas existe espaço para trabalhar a comunicação de uma determinada campanha, mas focada na 
sazonalidade ou produto em específico. No digital (e-commerce e redes sociais) o Grupo trabalha com as mesmas promoções e preços, mas aproveitam para desenvolver campanhas simultâneas, sejam elas distintas ou de aproximação. O conteúdo precisa alinhar objetivos da marca, dos públicos e permitir a livre circulação dos mesmos em todos os canais, com acesso igual aos conteúdos e toda facilidade praticada. É necessário harmonia na convivência entre as estratégias do e-commerce e dos franqueados na comunicação omnichannel. Este posicionamento é empregado pelo Grupo como forma de potencializar os relacionamentos e os negócios, eles acontecendo no on-line ou no off-line.

Conforme Guilherme, o Grupo ser omnichannel demonstra a jornada organizacional integrada por várias frentes. Comunicação, marketing, administração, logística, tecnologias de informação, todos articulados na busca e operacionalização das melhores estratégias. Articulação que se transmuta para as equipes de venda, atendimento e distribuição para que a experiência omnichannel seja legitima e eficaz. Para Guilherme, as experiências demandadas por todos os seus públicos, desde os mais conectados (omnichannel) até os menos conectados (primeiro e segundo canal), é uma preocupação verdadeira do Grupo Boticário.

\section{CONSIDERAÇÕES FINAIS}

Na atualidade é possível verificar a figuração das organizações em vários (e em alguns casos em todos) canais de comunicação e relacionamento. No entanto, como já mencionado, apenas figuram nestes espaços, não dedicando esforços para pesquisar e compreender sua mecânica e muito menos seus públicos/usuários. Ou, ainda, perceber suas potencialidades de negócio. Existe ainda um abismo entre negócios e comunicação digital. Campo que se abre para pesquisas que ajudem a diminuir esse espaço e tornem mais conscientes sua importância por parte das pessoas e organizações.

No que tange a ambiência omnichannel, sua usabilidade está em fase embrionária no Brasil. Em países da Europa e nos Estados Unidos, as organizações já utilizam com muito mais afinco esse conceito-prático e, já colhem os resultados quando se pensa em engajamento e lucratividade. No entanto, a bibliografia e a apresentação de cases e resultados sobre o omnichannel na comunicação ainda é pequena em comparação à outras vertentes.

Mas, com o breve estado da arte apresentado neste texto, é possível perceber as mudanças sociais que as tecnologias ainda implicam na vida das pessoas e organizações. A 
internet mudou e ainda vai mudar muito a forma como as sociedades vivem, se organizam e se comunicam. É fácil perceber a ressignificação do território de pertencimento social. As redes sociais digitais se apresentam e se consolidam como grandes responsáveis por todos os processos de desterritorialização e reterritorialização das pessoas e organizações ao redor do mundo. Mesmo a conectividade digital ser uma realidade de um pouco mais da metade da população mundial, é um caminho sem volta. E, também, um caminho cheio de possibilidades.

A compreensão das mudanças de cultura - mercado, clientes, tecnologias - implicam diretamente no modelo de gestão e também de sobrevivência das organizações. As pessoas já internalizaram à ubiquidade da vida. Agora é preciso que as organizações tenham a consciência que a sociedade hoje é desterritorializadas e reterritorializada digitalmente por meios de incomensuráveis plataformas de comunicação e relacionamento. Que a vida social, com o digital, é ubíqua e, nas redes sociais digitais, o cliente, seu público de interesse, suscita mudanças constantes no modo de se fazer negócios, de consumo, de comunicação e de relacionamento.

Para dar conta disso, as organizações precisam solidificar sua cultura organizacional, posicionar seu planejamento e a gestão das relações mercadológicas a partir do contexto operacional dessa comunicação omnichannel. Estando estruturadas e culturalmente propícias para viver a comunicação omnichannel, as organizações poderão acompanhar o público omnichannel. E ele - o público -, conseguindo o grau almejado de proximidade com sua marca, experienciando todas as sensações desejadas sem a necessidade de se deslocar, mesmo que simbolicamente, para outros espaços.

No breve relato sobre a experiência omnichannel do Grupo Boticário, todas essas afirmativas e apontamentos são visualizados, quando se identifica a mudança de posicionamento estratégico, as mudanças na cultura organizacional do grupo, o entendimento das necessidades, os desejos de seu público e, principalmente, o conhecimento sobre a comunicação em múltiplos canais. A integração e harmonia entre esses canais trazem como consequência, públicos mais informados, engajados, livres e aptos a consumir a marca em todos os espaços conforme seu desejo.

Percebe-se então, que as formas de relacionamento entre consumidor e marca são constantes e facilmente reinventadas. Portanto, cabe às organizações tornarem intrínseco o processo evolutivo de suas relações de negócio focado na cultura altamente mutável do 
mercado. A comunicação omnichannel é apenas uma das múltiplas transformações que o mercado está vivendo ou vivenciará, é apenas um exemplo onde as organizações precisarão, em modo de urgência, adaptar-se e promover sua sobrevivência.

Assim, este texto se encerra com a compreensão de que a vida na contemporaneidade é ubíqua. Isso sendo possível com as possibilidades de vivência on-line e off-line. Que essas mudanças tão instáveis afetam pessoas e organizações nas suas mais diferentes formas de relacionamento e comunicação. E, que a reflexão mais profunda sobre o conceito de omnichannel (comunicação e estratégia), é legitimada como forma de apresentar novos ou renovados modelos para relacionamentos e experiências em todos os canais e plataformas que uma marca/organização dispõe a serviços de seus públicos.

\section{REFERÊNCIAS}

BARICHELLO, Eugenia Mariano da Rocha. Mídia e Territorialidades. Animus: revista interamericana de comunicação midiática, vol. V, n. 1 (jan/jun 2006), UFSM, Santa Maria (RS), NedMidia, 2006.

Apontamentos sobre as estratégias de comunicação mediadas por computador nas organizações contemporâneas. In: KUNSCH, Margarida Maria Krohling (Org.). Comunicação organizacional: Histórico, fundamentos e processos. São Paulo: Saraiva, 2012.

CARDOSO, Gustavo. Sociedade em transição para a sociedade em rede. In: CASTELLS, Manuel; CARDOSO, Gustavo (Orgs.). A Sociedade em Rede: do conhecimento à ação política. Lisboa, Portugal. Imprensa Nacional - Casa da Moeda, 2005.

CASTELLS, Manuel. A Sociedade em Rede. 17. ed. São Paulo: Paz \& Terra, 2016.

. A Sociedade em Rede: do conhecimento à política. In. CASTELLS, Manuel; CARDOSO, Gustavo (Orgs.). A Sociedade em Rede: do conhecimento à ação política. Lisboa, Portugal. Imprensa Nacional - Casa da Moeda, 2005.

CHAMPS Agência. Omnichannel: comunicação feroz. Disponível em: < http://champsagencia.com/insights/comunicacao-omnichannel/>. Acesso em: 27 ago. 2020.

COELHO, Sandra Cristina Pereira. Desafios do omnichannel na aplicação às empresas nacionais. 2015. 71f. Dissertação (Mestrado em Engenharia de Serviços e Gestão). Universidade do Porto, 2015. Disponível em: < https://repositorio-aberto.up.pt/bitstream/10216/80133/2/36379.pdf >. Acesso em: 27 ago. 2020.

CORRÊA, Elizabeth Saad. Comunicação Digital: uma questão de estratégia e relacionamento com públicos. Revista Organicom. Ano 2, n. 03, 2ºmestre, 2005.

. Comunicação Digital e Novas Mídias Institucionais. In: KUNSCH, Margarida M. Krohling (Org.). Comunicação organizacional: Histórico, fundamentos e processos. São Paulo: Saraiva, 2012. 
DIAS, Suzana Wayand. O desafio do varejo multicanal: comportamento Free-riding do consumidor. 2014. 335f. Tese (Doutorado em Administração). Universidade de São Paulo, 2014. Disponível em: < https://www.teses.usp.br/teses/disponiveis/12/12139/tde-05092014-134326/pt-br.php > Acesso em: 27 ago. 2020.

FAGUNDES, Lígia. As perspectivas do omnichannel frente à comunicação integrada de marketing. In: Anais do $40^{\circ}$ Congresso Brasileiro de Comunicação de Ciências da Comunicação Curitiba, PR - 4 a 9 de setembro de 2017. Disponível em: <

http://portalintercom.org.br/anais/nacional2017/resumos/R12-0907-1.pdf>. Acesso em: 27 ago. 2020.

FARINELLI, Guilherme; VILLA, Gabriel. Franqueadoras on-line: novos caminhos e modelos de negócios. Palestra. VTEXDAY, 2017. Disponível em: https://www.youtube.com/watch?v=lpIIrt3zl04. Acesso em: 27 ago. 2020.

LÉVY, Pierre. O que é o virtual? 2a . ed. Rio de Janeiro: Editora 34, 2011.

MAINIERI, Tiago. Os Desafios da Comunicação Organizacional na era das Mídias Digitais. In: Anais do XXXIV Congresso Brasileiro de Comunicação de Ciências da Comunicação - Recife, PE 2 a 6 de setembro de 2011. Disponível em: <

http://www.intercom.org.br/papers/nacionais/2011/resumos/R6-1960-1.pdf>. Acesso em: 27 ago. 2020.

RECUERO, Raquel. Redes Sociais na Internet. 2a . ed. 1 ${ }^{\text {a }}$. reimp. Porto Alegre, RS: Sulina, 2014.

SANTAELLA, Lucia. Comunicação Ubíqua: repercussões na cultura e na educação. São Paulo: Paulus, 2013.

Original recebido em: 01 de março de 2020

Aceito para publicação em: 01 de maio de 2020.

\section{Fabio Frá Fernandes}

Doutorando no Programa de Pós-Graduação em Comunicação da Universidade Federal de Santa Maria (POSCOM/UFSM), mestre pelo Programa de Pós-Graduação em Comunicação e Indústria Criativa da Universidade Federal do Pampa (PPGCIC/Unipampa), bacharel em Comunicação Social, habilitação em Relações Públicas pela Universidade de Cruz Alta (UNICRUZ), com especialização em Comunicação Empresarial pela Universidade Metodista de São Paulo (UMESP). Pesquisa Comunicação Organizacional, Ambientes/Ecossistemas de Inovação e Indústria

Criativa à luz da Media Ecology e da teoria da Midiatização. Membro do grupo de pesquisa Comunicação Institucional e Organizacional (UFSM/CNPq) e do grupo de pesquisa em Processos e Práticas nas Atividades Criativas e Culturais (GPAC/CNPq/Unipampa). Foi professor substituto no

Bacharelado em Relações Públicas da Universidade Federal do Pampa (Unipampa/São Borja) e Relações Públicas da Universidade Regional do Noroeste do Estado do Rio Grande do Sul (UNIJUí). Atualmente desenvolve cooperação técnica à Comunicação Estratégica na Universidade Federal de Ciências da Saúde de Porto Alegre (UFCSPA). Os termos mais frequentes na contextualização de sua produção científica são: Relações Públicas, Comunicação Organizacional, Comunicação Midiática, 
Comunicação Institucional, Visibilidade Midiática, Universidade e Comunicação, Midiatização das Práticas Sociais, Media Ecology, Estratégias Comunicacionais, Indústria Criativa, Inovação, Tecnologia. ORCID: https://orcid.org/0000-0003-2035-6832

\section{Marcela Guimarães e Silva}

Professora Adjunta da Universidade Federal do Pampa (Unipampa campus São Borja). Professora permanente do Programa de Pós-Graduação em Comunicação e Indústria Criativa (PPGCIC/Unipampa), e do Bacharelado em Relações Públicas. Líder do grupo de pesquisa Processos e Práticas nas Atividades Criativas e Culturais (GPAC/CNPq). Coordenadora do Observatório Missioneiro das Atividades Criativas e Culturais (OMiCult/Unipampa). Bacharel em Relações Públicas pela Universidade Regional do Noroeste do Estado do Rio Grande do Sul (UNIJUÍ), especialista em Comunicação Midiática pela Universidade Federal de Santa Maria (UFSM), mestre e doutora em Extensão Rural também pela UFSM. Fez estágio de doutorado sanduíche com Bolsa CAPES - PDSE 16214-12-9, junto ao Laboratório de Comunicação e Conteúdos On-line da Universidade da Beira Interior (LabCom/UBI) em Portugal e estágio de pós-doutoramento em Comunicação e Gestão de Indústrias Criativas junto ao Center for research in communication, information and digital culture, da Faculdade de Letras da Universidade do Porto, Portugal (CIC.DIGITAL/FLUP/U.PORTO). ORCID: https://orcid.org/0000-0002-9752-2571

\section{(C) $(\mathcal{Q} \Theta($}

Esta obra está licenciada com uma Licença

Creative Commons Atribuição-NãoComercial-CompartilhaIgual 4.0 Internacional 